\title{
Optimization of selective laser sintering process conditions using stable sintering region approach
}

\author{
F. Lupone, E. Padovano*, M. Pietroluongo, S. Giudice, O. Ostrovskaya, C. Badini \\ Politecnico di Torino, Department of Applied Science and Technology, Corso Duca degli Abruzzi 24, 10129, Torino, Italy
}

Received 8 May 2020; accepted in revised form 16 July 2020

\begin{abstract}
The optimization of process parameters represents one of the major drawbacks of selective laser sintering (SLS) technology since it is largely empirical and based on performing a series of trial-and-error builds. This approach is time consuming, costly, and it ignores the properties of starting powders. This paper provides new results into the prediction of processing conditions starting from the material properties. The stable sintering region (SSR) approach has been applied to two different polymer-based powders: a polyamide 12 filled with chopped carbon fibers and polypropylene. This study shows that the laser exposure parameters suitable for successful sintering are in a range that is significantly smaller than the SSR. For both powders, the best combination of mechanical properties, dimensional accuracy, and porosity level are in fact, achieved by using laser energy density values placed in the middle of the SSR.
\end{abstract}

Keywords: mechanical properties, selective laser sintering, energy density, polyamide 12, polypropylene

\section{Introduction}

Selective laser sintering (SLS) is widely recognized as one of the most consolidated powder-based additive manufacturing techniques and has been widely investigated in recent years. During the SLS process, polymeric powders are deposited on the build platform by a recoater and selectively melted by means of a $\mathrm{CO}_{2}$ laser beam. The layer-by-layer repetition of powders spreading and laser exposure allows the consolidation of the objects and offers great flexibility in terms of part design and manufacturing $[1,2]$. Although many efforts have been spent to develop polymer-based powders for SLS, only a few materials are widespread adopted, namely polyamides and polyurethanes [3]. In fact, it was assessed that polymeric powders have to fulfill a demanding combination of intrinsic and extrinsic properties (i.e., suitable size and shape, thermal, rheological and optical behavior) to be processed by SLS [4, 5]. Moreover, it is well-known that the quality of SLS parts greatly depends on the adopted process parameters in addition to the properties of the powders. Nowadays, the optimization of SLS process parameters for a newly developed material remains a key challenge; this is mainly due to the complexity of process physics involved in laser sintering, which includes powders recoating, heat absorption, phase change, and particles coalescence $[6,7]$. Consequently, the temperature at which the part bed is pre-heated during the entire process (referred to as powder bed temperature) and the laser parameters should be tailored for each material.

It is generally accepted that for semicrystalline polymers, a powder bed temperature which lies between the onset of melting and the onset of crystallization must be adopted. This temperature range is commonly referred to as 'processing window', 'supercooling window', or 'glass window' [6]. It has to be as large as possible in order to avoid (or at least minimize) part curling during the building process due 
to premature crystallization. Apart from the supercooling window, polymer melting enthalpy should also be high enough to prevent the partial melting of the powder surrounding the printed part $[5,8]$.

Mechanical properties of produced parts are also greatly influenced by laser processing parameters. The optimization of these parameters to achieve proper part performances is usually carried out by using an empirical approach based on iterative trial and error builds. According to this method, one parameter is changed at a time, and its effect on porosity [9-11] and mechanical properties $[8,9,12-15]$ of sintered parts is evaluated. Most of the literature focuses on polyamide $12[9,12-14]$ and polyamide 12/carbon fiber composites [16-18]; however, a number of studies on polypropylene [15, 19, 20], thermoplastic polyurethane [8,21], poly(ether-etherketone) (PEEK) [22], polystyrene [23] and poly(ethylene terephthalate) (PET) [24] are also available. Although the design of experiments and statistical methods (ANOVA) are sometimes used [19, 25, 26], this strategy can be time-consuming and expensive depending on the material cost and recyclability and on the physical size of the used SLS machine.

The energy density supplied by the laser beam to the polymer has been frequently used by researchers as a first attempt to optimize SLS processing conditions. In fact, the increase of the energy density improves the fusion of particles and leads to higher mechanical properties. This finding has been described in literature from the earlier works of Caufield et al. [12] and Starr et al. [13] on polyamide 12 to more recent investigations [14, 22, 27].

In principle, the laser beam is expected to provide enough energy to fully melt the polymer, avoiding any detrimental effect such as part distortion or 'warping' or polymer degradation. Therefore, Vasquez et al. $[28,29]$ proposed a theoretical method, based on the definition of a 'stable sintering region' (SSR), to predict the proper SLS process parameters instead of the empirical trial and error approach. The model was employed to identify an energy density interval to obtain a successful sintering process through the evaluation of the volume energy required to melt and induce the degradation of polyamide 12 powders, respectively. Thermal properties of the powders, obtained from DSC and TGA analyses, and other important factors, such as bed temperature and powder packing density, were taken into consideration. It was found that the mechanical properties progressively improved by increasing the value of energy density within the stable sintering region; this growing trend was observed until the predicted degradation point is reached. The stable sintering region combined with the 'energy melt ratio' (EMR) (which was introduced by Starr et al. [13]) was therefore proposed as the main parameters to optimize SLS processing conditions.

Berretta et al. [22] employed this method to predict the process parameters in high-temperature laser sintering of poly(ether-ether-ketone) powder. It was found that the mechanical properties of the sintered samples constantly improve with the increase of laser energy input; however, the tensile strength of the components did not decrease once the predicted degradation point is reached. Therefore, the authors stated that the SSR method represents a good starting point for the optimization of laser parameters; however, a correction of the equation describing polymer degradation is advised. It could be inferred that the rapid heating-cooling cycles induced by laser exposure highly differ from the experimental conditions encountered during thermal gravimetric analysis. Therefore, the determination of the degradation limit could be inaccurate.

Finally, Yuan et al. [27] used a similar model to optimize the SLS processing conditions of carbon nanotubes/polyamide 12 nanocomposite powders. Not surprisingly, tensile strength, elastic modulus, and elongation at break progressively increased with the increase of energy density, reaching desirable performances above a critical energy density value.

The interest in developing new polymers specifically designed for SLS has constantly been growing; in fact, in the last years, several polymer composites were investigated due to their potential for structural and functional applications [3]. Therefore, the formulation of a method that provides a systematic way to optimize a priori the SLS process conditions for promising candidates would entail great interest.

The melting and degradation energy values obtained in previous studies on polyamide and PEEK systems $[22,27,29]$ showed that, in principle, the SLS process could be performed by using laser energy inputs included in rather large intervals. However, parts produced by SLS have to fulfill certain requirements in order to be adopted in an industrial environment. In addition, only a small deviation of the part dimensions from the CAD design could be accepted. Therefore, processing conditions causing poor precision 
or even sample distortion due to severe thermal gradients should be discarded [14, 30].

In this context, the main purpose of this work is to exploit the stable sintering region method with the aim of further narrow the suitable range of energy density, and therefore of laser parameters for a successful SLS process. The proposed approach takes into consideration the best combination of experimentally measured mechanical properties, parts accuracy, and defect content of printed parts. This experimental work could be beneficial to deepen the study of process-structure-properties relationship in materials processed by SLS. Two semicrystalline polymer-based powders that highly differ in terms of chemical, thermal and morphological properties, such as polyamide 12 /carbon fiber composite and polypropylene, were tested to assess its general validity.

\section{Experimental section \\ 2.1. Materials}

Two polymeric based powders, specifically short carbon fiber reinforced polyamide 12 and polypropylene, were purchased from ADVANC3D Materials ${ }^{\circledR}$ $\mathrm{GmbH}$ (Hamburg, Germany) respectively under the brand name of 'AdSint PA12CF' (PA12/CF) and 'AdSint PP Flex' (PP). AdSint PA12CF is based on Orgasol ${ }^{\circledR}$ polyamide 12 powder produced by Arkema (Colombes, France) through direct polymerization (anionic ring-opening polymerization from monomer solution [31]). The powder is then optimized and dry mixed with short carbon fibers. AdSint PP is produced by cryogenic milling from isotactic polypropylene pellets.

\subsection{Powders characterization techniques}

The morphology and the particle size distribution of the powders were investigated by using a field emission scanning electron microscope FESEM Zeiss MERLIN (Carl Zeiss Microscopy GmbH, Jena, Germany). Low magnification micrographs $(500 \times)$ were processed through Image ${ }^{\circledR}$ software to measure the dimensions of 300 particles, thus obtaining an accurate evaluation of particle size distribution of both powders. Similarly, the length distribution of carbon fibers in PA12/CF material was also assessed.

The true density of the powders was measured by a pycnometer according to ASTM D792-13 standard and using ethanol as the immersion liquid. The bulk and tap density were determined by filling a $25 \mathrm{~cm}^{3}$ container with the powder and manually tapping it according to a simplified procedure based on ASTM D7481 standard and reported elsewhere $[32,33]$. The packing factor $(\varphi)$ and the Hausner ratio $(H R)$, commonly used to describe bulk and flow behavior of polymer powders for laser sintering [34], were then calculated by using the Equations (1) and (2) respectively:

$\Phi=\frac{\rho_{\text {bulk }}}{\rho}$

$H R=\frac{\rho_{\text {tap }}}{\rho_{\text {bulk }}}$

where $\rho_{\text {bulk }}, \rho_{\text {tap }}$ and $\rho$ are the apparent, tapped and true density of the powders respectively.

X-ray diffraction (PANalytical PW3040/60 X'Pert $\mathrm{PRO}$ diffractometer with $\mathrm{Cu}-\mathrm{K} \alpha$ radiation at $40 \mathrm{kV}$ and $40 \mathrm{~mA}, 2 \theta$ range from 10 to $50^{\circ}$ with a step size of $0.013^{\circ}$ ) was performed to identify the crystalline phases of the raw powders as well as the sintered samples.

The thermal properties of the powders were investigated by Differential Scanning Calorimetry (DSC) and Thermal Gravimetric Analysis (TGA). DSC experiments were carried out under argon flow ( $50 \mathrm{ml} / \mathrm{min}$ ) by using a PerkinElmer Pyris 1 equipment (PerkinElmer Inc., Waltham, MA, USA). A heating-cooling program from room temperature up to $230^{\circ} \mathrm{C}$ (for PA12/CF) or $200^{\circ} \mathrm{C}$ (for PP) with a rate of $10^{\circ} \mathrm{C} / \mathrm{min}$ were carried out to characterize the melting and crystallization behavior of the powders. The crystalline fraction $X_{\mathrm{C}}$ of the polymer was estimated from the area of the melting peak by using Equation (3):

$X_{\mathrm{C}}=\frac{\Delta H_{\mathrm{m}}}{\Delta H_{\mathrm{m}}^{0}(1-f)} \cdot 100$

where $\Delta H_{\mathrm{m}}$ is the melting enthalpy, $\Delta H_{\mathrm{m}}^{0}$ is the $100 \%$ crystalline melting enthalpy (209.3 and $177 \mathrm{~kJ}$ for PA12 and PP respectively $[18,20])$ and $f$ is the mass fraction of filler. The same experiments were also performed to analyze the crystallinity of the sintered samples.

The DSC equipment was also used to measure the specific heat capacity of powders and melted polymers as a function of temperature. The step-scan method accomplishing the ASTM E1269-11 standard was adopted to this purpose [35]. The specific heat was evaluated in the temperature ranges of 50-240 
and $40-200^{\circ} \mathrm{C}$ for PA $12 / \mathrm{CF}$ and PP, respectively, with a step of $5^{\circ} \mathrm{C}$.

The thermal degradation process of the powders was investigated by TGA tests carried out by heating the samples in air or in argon atmosphere from room temperature to $800^{\circ} \mathrm{C}$ in a Mettler-Toledo TGA/ SDTA 851e instrument. The experiments performed under inert atmosphere (with a heating rate of $10^{\circ} \mathrm{C} / \mathrm{min}$ ) were used to determine the content of carbon fibers in PA12/CF powders by considering the residue left after polyamide pyrolysis. The TGA experiments carried out in air were instead recorded at different heating rates $\left(5,10\right.$ and $\left.20^{\circ} \mathrm{C} / \mathrm{min}\right)$ in order to study the thermo-oxidative degradation process of the polymeric powders that occurs during SLS operations (see Section 2.2). The onset degradation temperature was determined when $1 \%$ weight loss occurs during the TGA experiment performed in an air atmosphere with a heating rate of $10^{\circ} \mathrm{C} / \mathrm{min}$. The activation energy $\left(E_{\mathrm{A}}\right)$ was evaluated through the Kissinger method [36] by using Equation (4):

$\ln \left(\frac{\beta}{T_{\max }^{2}}\right)=-\frac{E_{\mathrm{A}}}{R}\left(\frac{1}{T_{\max }}\right)+\ln \left(\frac{A R}{E_{\mathrm{A}}}\right)$

where $\beta$ is the heating rate, $T_{\max }$ is the temperature corresponding to the maximum degradation rate and $R$ is the gas constant. The experimental data of $\ln \left(\beta / T_{\max }^{2}\right)$ plotted versus $1 / T_{\max }$ were fitted by linear regression and $E_{\mathrm{A}}$ was calculated from the straightline slope multiplied by $R$.

\subsection{Selective laser sintering and theoretical background}

The direct laser sintering machine Sharebot SnowWhite (Sharebot S.r.l., Nibionno, Italy) equipped with continuous-wave $\mathrm{CO}_{2}$ laser emitting at $10.6 \mu \mathrm{m}$ wavelength was used to process the powders. The laser has a $200 \mu \mathrm{m}$ focus diameter and can generate power up to $14 \mathrm{~W}$. The build area is pre-heated by four IR lamps, and a recoating blade is used to spread the powders over it. Unlike other commercial LS machines, Sharebot SnowWhite operates in an air environment.

The optimization of process parameters has been performed using the stable sintering region method introduced by Vasquez et al. [29]. This method allows us to predict the temperature range that promotes the complete melting of powder particles during laser exposure while avoiding material degradation. However, it is more meaningful to analyze the SLS process in terms of energy rather than temperature. Therefore, the stable sintering region is usually defined in terms of energy densities for polymer melting and degradation.

Equations formerly proposed in the literature were slightly modified to take into account the different contributions to the polymer degradation process. Both the energy required to melt the powders and the energy that leads the material from the melting point to the onset of degradation need to be accounted for. The thermal degradation process in the air atmosphere was considered because the SLS machine used operates in an air environment. The newly proposed equations are presented in the following.

The lower limit of the stable sintering region, corresponding to the volume energy required to melt the polymeric powder $\left(E_{\mathrm{m}}\right)$, was calculated taking into account the energy necessary to heat the powders from the bed temperature to the melting point and the energy needed for the melting process according to Equation (5):

$E_{\mathrm{m}}=\left[C_{\mathrm{p}}^{\text {powder }}\left(T_{\mathrm{m}}-T_{\mathrm{b}}\right)+h_{\mathrm{f}}\right] \rho \Phi$

where $T_{\mathrm{m}}$ and $T_{\mathrm{b}}$ are the melting and powder bed temperatures respectively, $C_{\mathrm{p}}^{\text {powder }}$ is the value of specific heat at powder bed temperature, $h_{\mathrm{f}}$ is the melting enthalpy, $\rho$ is the true density of the powders and $\Phi$ is the packing factor.

The upper limit that corresponds to the theoretical volume energy to obtain the material degradation $\left(E_{\mathrm{deg}}\right)$, is usually defined considering both the energy necessary to heat the material up to the onset degradation temperature and the energy required to overcome the activation energy for degradation. This study slightly modifies $E_{\text {deg }}$ calculation by adding to the previously reported contributions the term indicating the powder melting enthalpy (introduction of $E_{\mathrm{m}}$ and, as consequence, $T_{\mathrm{b}}$ is substituted by $T_{\mathrm{m}}$ ). This allows us to calculate $E_{\operatorname{deg}}$ according to Equation (6):

$E_{\text {deg }}=E_{\mathrm{m}}+\left[C_{\mathrm{p}}^{\mathrm{melt}}\left(T_{\mathrm{deg}}-T_{\mathrm{m}}\right)+\frac{E_{\mathrm{A}}}{M_{\mathrm{w}}}\right] \rho$

where $C_{\mathrm{p}}^{\text {melt }}$ is the specific heat at temperatures above the melting point, $T_{\mathrm{deg}}$ is the onset temperature for degradation in air; $E_{\mathrm{A}}$ is the activation energy for the degradation process, $M_{\mathrm{w}}$ is the polymer weight-average molecular weight. The parameters used for the evaluation of the energy required for melting and degradation were experimentally determined from 
calorimetric and physical tests; on the contrary, $M_{\mathrm{w}}$ was obtained from the literature.

The energy delivered by the laser beam to the polymer during an SLS building operation should be sufficiently high to fully melt the powders. In addition, this energy value should keep the temperature within the stable sintering region below the critical energy of degradation. The laser energy input is generally defined as 'volume energy density' $\left(E_{\mathrm{D}}\right)$ according to Equation (7):

$$
E_{\mathrm{D}}=\frac{P}{v S z}
$$

where the laser power $(P)$, the beam velocity ('scan speed,' $v$ ), the distance between two subsequent scans of laser exposure ('hatching distance,' $S$ ) and the layer height $(z)$ are used to describe the amount of the energy given by the machine to the powder bed.

Several sets of specimens were produced, adopting different laser energy inputs selected in between the lower and the upper limits of the previously mentioned stable sintering region and then characterized. The most critical parameters, such as the laser power $P$ and the scan speed s, were varied, leading to an increase of energy density values, as briefly summarized in Table 1. Hatching distance and layer height were instead set at a constant value of $100 \mu \mathrm{m}$.

With this experimental design, it was possible to explore the stable sintering region defined from powders properties. The most convenient powder bed temperature was selected between the melting and crystallization onsets of materials in order to minimize part curling.

Flat dog-bone specimens according to 1BA geometry of ISO $527-2$ standard (dimensions $75 \times 5 \times 3 \mathrm{~mm}$ ) were printed for tensile tests. Square samples with dimensions $10 \times 10 \times 5 \mathrm{~mm}$ were produced to investigate the microstructure induced by the layer-wise process and to evaluate parts dimensional accuracy and density. All specimens were built-up in the XY plane using a $0 / 90^{\circ}$ scanning strategy. The building plate is on XY plane, and the recoater moves along the $x$-axis. Four dog-bones and two square samples were printed for each set of parameters. Tensile tests were carried out according to ISO 527-2 standard by using an MTS Criterion Model 43 testing system (MTS Systems S.r.1., Italy) with a $5 \mathrm{kN}$ load cell. The strain rate of $1 \mathrm{~mm} / \mathrm{min}$ was used for PA12/CF specimens, while PP parts were tested at $5 \mathrm{~mm} / \mathrm{min}$. The strain was measured by means of a $25 \mathrm{~mm}$ length extensometer.

Printing accuracy was evaluated measuring the deviations from the correct dimensions of the sintered $10 \times 10 \times 5 \mathrm{~mm}$ samples with a digital caliper. The average deviation per unit length was determined considering the mean value of the dimensional error along $x$ (length), $y$ (width), and $z$ (thickness) axis. Bulk density of sintered samples was measured by the Archimede method according to ASTM B962-17 standard using ethanol as the immersion liquid. Porosity content $\left(X_{\mathrm{P}}\right)$ were determined according to Equation (8):

$X_{\mathrm{P}}=\left(1-\frac{\rho_{\mathrm{SLS}}}{\rho}\right) \cdot 100$

where $\rho_{\mathrm{SLS}}$ is the density of the sintered samples and $\rho$ is the true density of the powders.

Optical microscopy (Leica DMI 5000 M, Leica Microsystems $\mathrm{GmbH}$, Wetzlar, Germany) was used to investigate the microstructure and the pore morphology of the sintered samples. Cross-sections were obtained by cutting the samples in parallel (YZ plane) and perpendicular (XY plane) directions with respect to the building one, by using Buehler IsoMet ${ }^{\circledR} 4000$ precision saw (Buehler, Lake Bluff, IL, USA). The specimens were then mounted in epoxy resin and

Table 1. Process parameters, resulting in different laser energy densities, used for SLS processing trials for PA12/CF and PP powders. Hatching distance and layer height were always set at $100 \mu \mathrm{m}$.

\begin{tabular}{|c|l|c|c|}
\hline \multicolumn{1}{|c|}{ Material } & Fixed parameters & $\begin{array}{c}\text { Laser power } \\
{[\mathbf{W}]}\end{array}$ & $\begin{array}{c}\text { Scan speed } \\
{[\mathbf{m m} / \mathbf{s}]}\end{array}$ \\
\hline \multirow{3}{*}{$\mathrm{PA} 12 / \mathrm{CF}^{\mathrm{a}}$} & $T_{\text {bed }}=170^{\circ} \mathrm{C}$ & $2.8-3.5-4.2-4.9-5.6-6.3-7$ & 2400 \\
& $S=100 \mu \mathrm{m}$ & $2.8-3.5$ & 1440 \\
& $h=100 \mu \mathrm{m}$ & $2.8-3.5$ & 960 \\
\hline & & 5.6 & $3120-1680$ \\
\hline $\mathrm{PP}^{\mathrm{a}}$ & $T_{\text {bed }}=120{ }^{\circ} \mathrm{C}$ & $2.8-3.5-4.2-4.9-5.6$ & 3800 \\
& $S=100 \mu \mathrm{m}$ & 2.8 & 3120 \\
& $h=100 \mu \mathrm{m}$ & 2.8 & 3000 \\
\hline
\end{tabular}

${ }^{\mathrm{a}}$ Material shrinkage along $x$ and $y$ axis was set as 3.5\% for PA12/CF and 5\% for PP. 
manually polished using standard metallographic preparation techniques ( $\mathrm{SiC}$ abrasive papers up to 4000 grit and a napped cloth for diamond paste polishing with surface finishing of $1 \mu \mathrm{m}$ ).

Optical microscopy was also used to investigate the fiber orientation in sintered PA12/CF tensile specimens. To this purpose, $100 \times$ magnification images of several XY cross-sections were elaborated by image analysis through Image ${ }^{\circledR}$ software. The images were processed following a procedure similar to the one proposed by Jansson and Pejryd [16] in a previous paper. The orientation of about 1500 carbon fibers was then assessed, calculating the angle formed between the fiber and the $x$-axis, which correspond to the recoater movement direction.

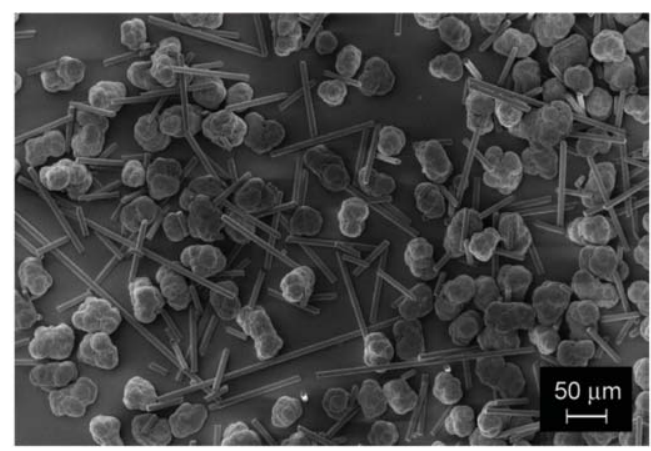

a)

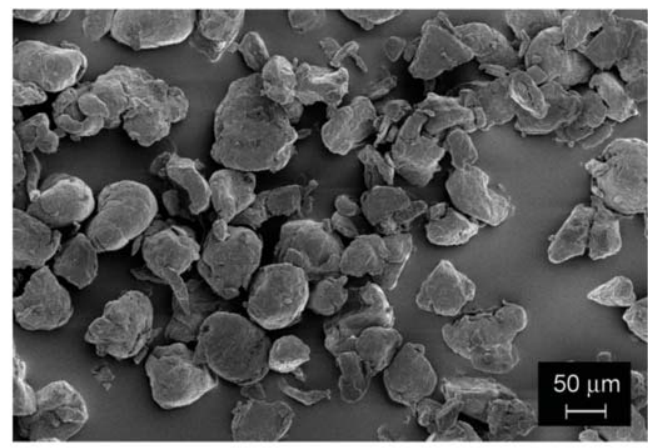

c)

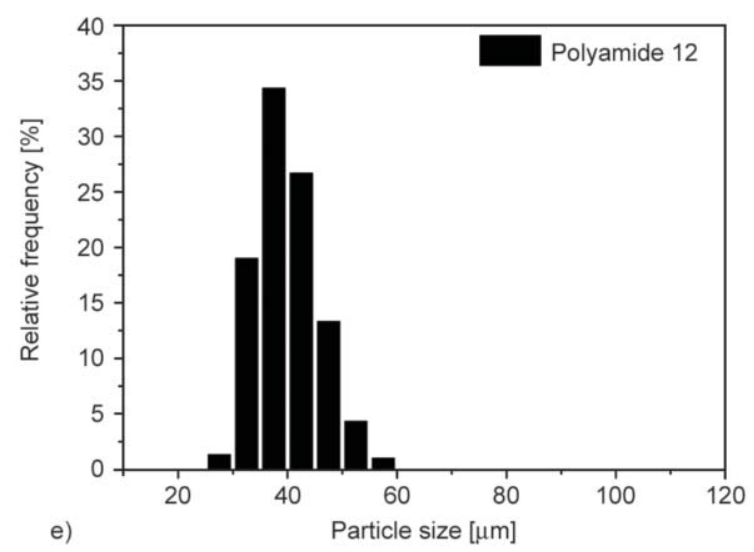

\section{Results and discussion}

\subsection{Powders characterization}

The morphology and particle size distribution of PA12/CF and PP powders is depicted in Figure 1. Differences in shape, surface structure, and size of polymer particles can be clearly recognized as a consequence of the different methods used for the production of the powders.

PA12/CF, a mixture of Orgasol ${ }^{\circledR}$ polyamide 12 powder and chopped carbon fibers, exhibits rather homogeneous dimensions and a nearly regular cauliflowerlike morphology with a wavy surface structure (Figure 1a). At higher magnification, a stacked layered assembly which consists of lamellae of the polymer crystalline phase is clearly visible (Figure 1b).

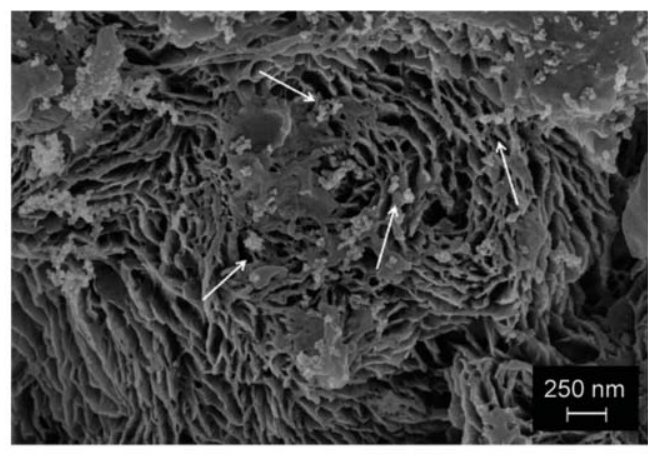

b)

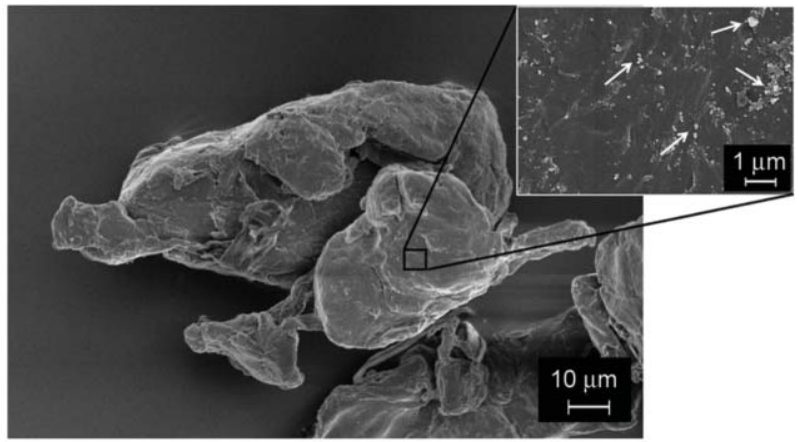

d)

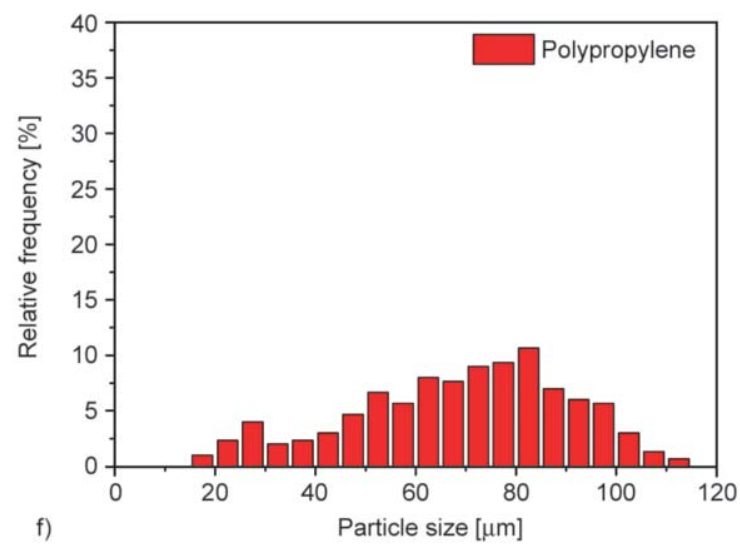

Figure 1. Scanning electron microscope images of (a, b) PA12/CF and (c, d) PP powders. Polymer particles size distribution obtained with Image ${ }^{\circledR}$ software: (e) PA12/CF and (f) PP. 
Specifically, the X-ray diffraction pattern of the powder displays a broad signal that is typical of glassy amorphous structures; in addition, a sharp peak at $2 \theta=21.37^{\circ}$ corresponding to the Miller index (100) of $\gamma$ crystalline structure of polyamide 12 can be observed [37].

On the other hand, PP powders present irregular shape and size with sharp edges and smooth surfaces as a result of the cryogenically milling process; some elongated particles are also visible (Figure 1c, 1d). The X-ray spectrum of the powders evidenced the presence of both amorphous and crystalline fractions. Several diffraction peaks (at $2 \theta=14.2,17.1,18.6$, $21.1,21.9,25.7$, and $28.5^{\circ}$ ) characteristics of the $\alpha$ crystalline phase of polypropylene were identified [20, 38].

In addition, very small round particles (few tens of nanometers in size) can be observed in high magnification FESEM images of both PA12/CF and PP powders (they are put in evidence by white arrows in Figure $1 \mathrm{~b}$ and the inset of Figure 1d). These particles are inorganic additives used as flow agents. In fact, drycoating or mixing of polymeric powders with $\mathrm{SiO}_{2}$ or carbon black nanoparticles is reported to be a valuable method to improve powders flowability [39].

The granulometric analysis of the powders gives a clear indication that the particle size distribution is narrow in the case of polyamide powders (ranging from 30 to $60 \mu \mathrm{m}$, Figure 1e), while polypropylene ones present a remarkably larger dimensional distribution (from 20 to $115 \mu \mathrm{m}$, Figure 1f). Moreover, it is important to notice that PP shows a bimodal particle size distribution with a significant number of small particles; these are usually present in cryogenically milled powders.

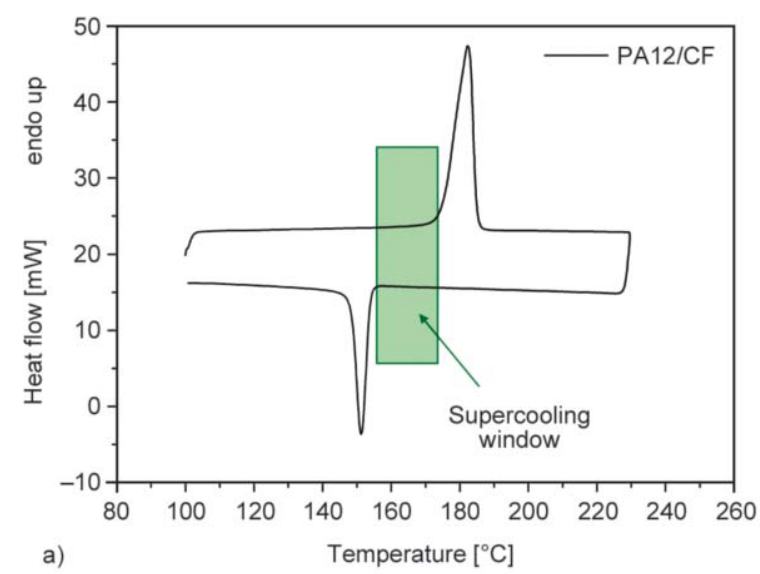

Table 2. True density, packing factor and Hausner ratio of PA12/CF and PP powders.

\begin{tabular}{|l|c|c|c|}
\hline Material & $\begin{array}{c}\text { True densitym, } \boldsymbol{\rho} \\
{\left[\mathbf{g} / \mathbf{c m}^{\mathbf{3}}\right]}\end{array}$ & $\begin{array}{c}\text { Packing factor, } \\
\mathbf{\Phi}\end{array}$ & $\begin{array}{c}\text { Hausner ratio, } \\
\boldsymbol{H R}\end{array}$ \\
\hline PA12/CF & $1.08 \pm 0.01$ & 0.41 & $1.28{\text { (fair })^{1}}^{1}$ \\
\hline PP & $0.89 \pm 0.01$ & 0.35 & 1.29 (fair) $^{1}$ \\
\hline
\end{tabular}

${ }^{1}$ Classification according to [40].

Carbon fibers with a diameter of about $7 \mu \mathrm{m}$ and a length distribution ranging between 20 and $310 \mu \mathrm{m}$ were used as reinforcement in PA12/CF powders. The surface of the fibers is clean and rough, with many parallel grooves distributed along their longitudinal axis.

The true density, packing factor, and Hausner ratio of both powders are reported in Table 2. The packing factor $(\Phi)$ indicates the ability of the powders to occupy a specific volume, while the Hausner ratio allows us to classify the powder flowability [40].

These results showed that PA12/CF powders appear to be more suitable for SLS technology. In fact, it is well-known that polymeric powders that present near-spherical shape and narrow particle size distribution (i.e. between 20 and $80 \mu \mathrm{m}$ ) are more effective to be processed in SLS machines [5]. The large particle size distribution and the angular and edgy shape of PP powders may negatively affect the packing density and processability of the material. As a consequence, the powder bed density decreases, leading to the production of sintered components with low part density; this, in turn, would worsen their mechanical properties [34] (Section 3.3.2).

The DSC curves of the two powders are shown in Figure 2. The melting and crystallization peaks and the presence of the 'supercooling window' can be observed in both curves. PA12/CF shows a wide

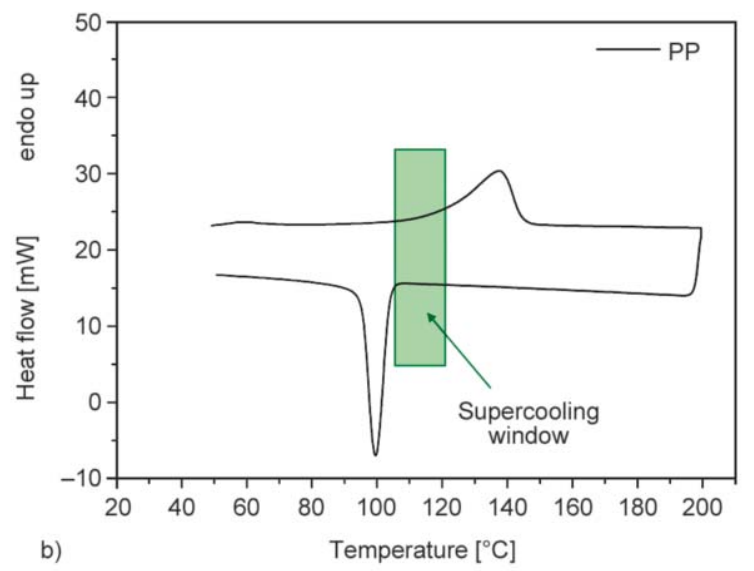

Figure 2. This DSC curves of (a) PA12/CF and (b) PP powders. The extent of 'the supercooling window' is underlined in the figure. 
temperature range between the onset of melting and the onset of crystallization events. Moreover, sharp and well-defined melting and crystallization peaks with a high enthalpy of fusion are clearly visible (Figure $2 \mathrm{a}$ ); they are related to the high crystalline fraction and crystallite perfection of raw powders [5]. In comparison, PP shows a relatively smaller supercooling window with a broad melting peak (Figure 2b). A sharp crystallization peak with a high crystallization enthalpy is clearly observed, leading to a strong tendency to shrinkage during cooling. These characteristics were reported to be the reason why polypropylene is more challenging to be processed by SLS than polyamide-based materials [19].

The melting behavior of PP powder also indicates that the requirement of thermal energy is reduced with respect to PA12/CF, although the advantage of lasers (that is delivering a huge amount of energy in a short time) is not exploited. Transitions temperatures and enthalpy values of PA12/CF and PP are reported in Table 3.

By using a modulated DSC experiment [35], the specific heat capacity was measured as a function of the temperature. The heat capacity of the powders gradually increases with temperature, while the specific heat of molten polymers remains almost constant. $\mathrm{PA} / 12 \mathrm{CF}$ always displays lower values than PP. The heat capacity at powder bed temperature and the average value of heat capacity of the liquid phase, reported in Table 3, are used to determine the melting and degradation energy, respectively (Section 3.3).

The stable sintering region (SSR) was determined by combining the DSC and TGA curves. PA12/CF exhibits a wider temperature interval between the offset of melting and the onset of degradation in air than PP (Figure 3a). Since it is generally recognized that polymers with wide SSR are more desirable for the LS technology [1], it can be assumed that the

Table 3. Materials properties for PA12/CF and PP powders relevant to melting and degradation energy evaluations.

\begin{tabular}{|c|c|c|c|c|}
\hline \multicolumn{3}{|c|}{ Properties } & \multirow{2}{*}{$\begin{array}{c}\text { PA12/CF } \\
174.7\end{array}$} & \multirow{2}{*}{$\begin{array}{c}\mathbf{P P} \\
120.0\end{array}$} \\
\hline Onset melting temperature & $T_{\mathrm{m} \text { onset }}$ & {$\left[{ }^{\circ} \mathrm{C}\right]$} & & \\
\hline Melting peak & $T_{\mathrm{m}}$ & {$\left[{ }^{\circ} \mathrm{C}\right]$} & 182.3 & 137.5 \\
\hline Endset melting temperature & $T_{\mathrm{m} \text { endset }}$ & {$\left[{ }^{\circ} \mathrm{C}\right]$} & 184.9 & 144.5 \\
\hline Enthalpy of melting & $h_{\mathrm{f}}$ & {$[\mathrm{J} / \mathrm{g}]$} & 81.41 & 59.45 \\
\hline Onset crystallization temperature & $T_{\mathrm{c} \text { onset }}$ & {$\left[{ }^{\circ} \mathrm{C}\right]$} & 153.9 & 103.7 \\
\hline Enthalpy of crystallization & $h_{\mathrm{c}}$ & {$[\mathrm{J} / \mathrm{g}]$} & 39.2 & 38.7 \\
\hline Powder specific heat & $C_{\mathrm{p}}^{\text {powder }}$ & {$[\mathrm{J} /(\mathrm{g} \cdot \mathrm{K})]$} & 1.99 & 3.47 \\
\hline Melt specific heat & $C_{\mathrm{p}}^{\text {melt }}$ & {$[\mathrm{J} /(\mathrm{g} \cdot \mathrm{K})]$} & 1.81 & 2.01 \\
\hline Onset degradation temperature in air & $T_{\mathrm{deg}}$ & {$\left[{ }^{\circ} \mathrm{C}\right]$} & 369 & 280 \\
\hline Activation energy & $E_{\mathrm{A}}$ & {$[\mathrm{kJ} / \mathrm{mol}]$} & 361.1 & 147.3 \\
\hline Weight average molecular weight & $M_{\mathrm{w}}$ & {$[\mathrm{g} / \mathrm{mol}]^{1}$} & 18080 & 7500 \\
\hline Supercooling window & & {$\left[{ }^{\circ} \mathrm{C}\right]$} & 21 & 16 \\
\hline Stable sintering region & & {$\left[{ }^{\circ} \mathrm{C}\right]$} & 184 & 136 \\
\hline
\end{tabular}

${ }^{1}$ Molecular weight was obtained from literature data $[9,41]$.
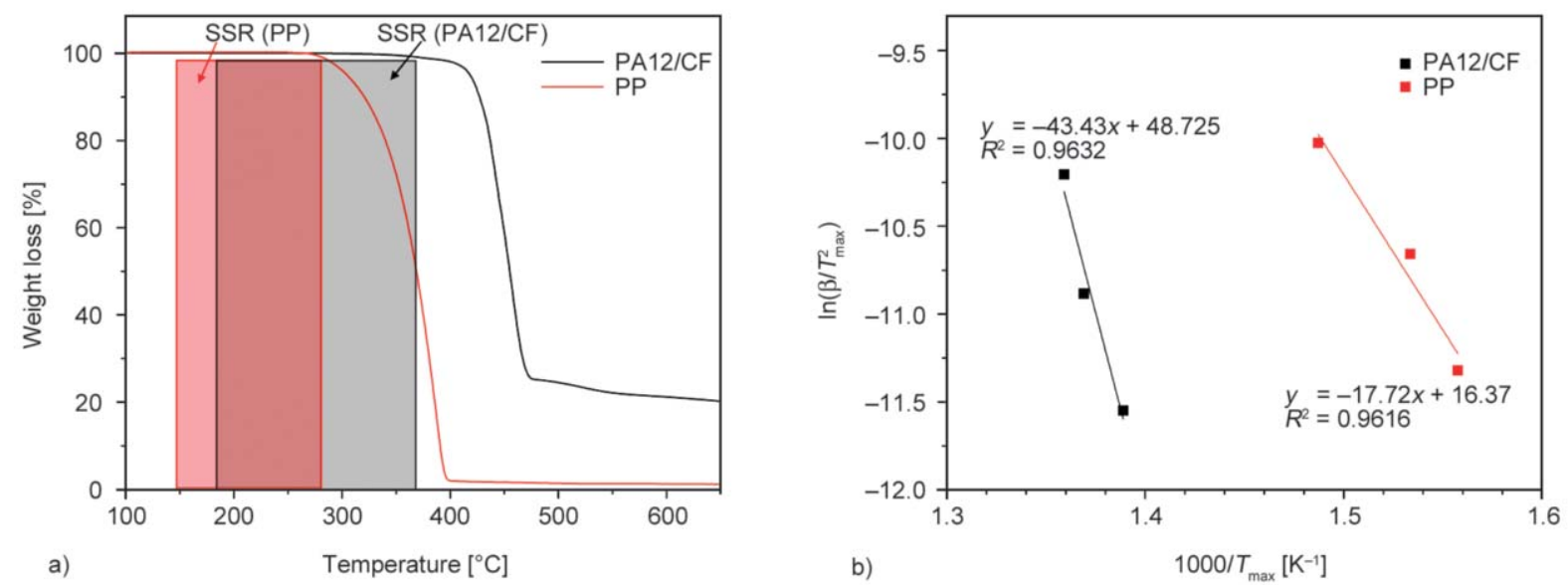

Figure 3. (a) TGA curves of PA12/CF and PP showing the stable sintering region measured by combining DSC and TGA analysis; (b) Kissinger's plot obtained from TGA experimental data at different heating rate. 
optimization of process parameters is easier in the case of PA12/CF.

TGA analysis was also employed to determine the content of carbon fibers in PA12/CF powders and the activation energy for thermo-oxidative degradation of both materials. The content of carbon fibers (19.2\%) was obtained by subtracting the weight of unreinforced PA12 carbonaceous residue from the weight of the residue of PA12/CF after TGA experiments performed in an argon atmosphere. Activation energy values of $362.8 \mathrm{~kJ} / \mathrm{mol}$ (with a correlation coefficient of 0.963 ) and $147.3 \mathrm{~kJ} / \mathrm{mol}$. (correlation coefficient of 0.962 ) were calculated for PA12/CF and PP, respectively, using the Kissinger method (Figure 3b).

The thermal properties that are significant for melting and degradation energy evaluations are summarized in Table 3. The molecular weight of PA12 and $\mathrm{PP}$ was assessed according to data found in the literature $[9,41]$. The packing factor and true density of powders were already reported in Table 2 , while powder bed temperature was determined experimentally, as described in Section 3.2.

\subsection{Powder bed temperature}

It is generally recognized that in SLS processing of semicrystalline polymers, the power bed temperature $\left(T_{\mathrm{b}}\right)$ should be set in-between the melting and crystallization onsets. The differential scanning calorimetry curves (Figure 2) showed that this temperature range is slightly different for the materials under investigation $\left(21^{\circ} \mathrm{C}\right.$ for PA12/CF and $16^{\circ} \mathrm{C}$ for $\left.\mathrm{PP}\right)$. Obviously, the powder bed should be pre-heated up to a temperature that is lower than the melting onset. This is required to avoid that polymer powders start melting outside the areas that are exposed to the laser beam, leading to powder bed caking. On the other hand, $T_{\mathrm{b}}$ should be kept close to the melting point because the crystallization of the polymer is slow enough to avoid the build-up of thermal stresses during the sintering process, and thus part curling.

Trial and error experiments were carried out to identify the value of $T_{\mathrm{b}}$. Several $1 \mathrm{~mm}$ thick hexagonal sheets were sintered pre-heating the powder bed at different temperatures, starting $10^{\circ} \mathrm{C}$ below the melting onset. The temperature was gradually increased until no part deformation occurred, and the powders can be easily spread by the recoater at once. This procedure suggests that $T_{\mathrm{b}}$ close to the polymer melting point has to be set for both powders $\left(170^{\circ} \mathrm{C}\right.$ for
PA12/CF and $120^{\circ} \mathrm{C}$ for PP). Therefore, the definition of the supercooling window is a reliable method for these materials.

\subsection{Evaluation of energy density to determine the stable sintering region}

The temperature range of the stable sintering region defined in Section 3.1 can be exploited to quantitatively determine the energy density required for the melting and degradation of PA12/CF and PP powders (Table 4). Energy intervals of 0.046-0.410 and $0.037-0.294 \mathrm{~J} / \mathrm{mm}^{3}$ were established for successful laser sintering of PA12/CF and PP powders, respectively. In both cases, the stable sintering region is rather large: 0.363 and $0.256 \mathrm{~J} / \mathrm{mm}^{3}$ for PA12/CF and $\mathrm{PP}$, respectively.

\subsection{Effect of energy density on mechanical properties, microstructure and dimensional accuracy}

\subsubsection{PA12/CF}

Figure 4 shows the variation of tensile strength, porosity, and dimensional accuracy (in terms of deviation per unit length from CAD design) of sintered PA12/ CF specimens as a function of laser energy density. The tensile strength remarkably increased by increasing the laser energy density; strength values of about $50 \mathrm{MPa}$ at an energy density of $0.23-0.24 \mathrm{~J} / \mathrm{mm}^{3}$ were obtained. Mechanical properties remained nearly

Table 4. Volume energy densities required for melting and degradation of PA12/CF and PP powders.

\begin{tabular}{|lll|c|c|}
\hline \multicolumn{3}{|c|}{ Energy parameters } & PA12/CF & PP \\
\hline Energy required for melting & $E_{\mathrm{m}}$ & {$\left[\mathrm{J} / \mathrm{mm}^{3}\right]$} & 0.046 & 0.037 \\
\hline Energy required for degradation & $E_{\mathrm{deg}}$ & {$\left[\mathrm{J} / \mathrm{mm}^{3}\right]$} & 0.410 & 0.294 \\
\hline Energy range for SSR & {$\left[\mathrm{J} / \mathrm{mm}^{3}\right]$} & 0.363 & 0.256 \\
\hline
\end{tabular}

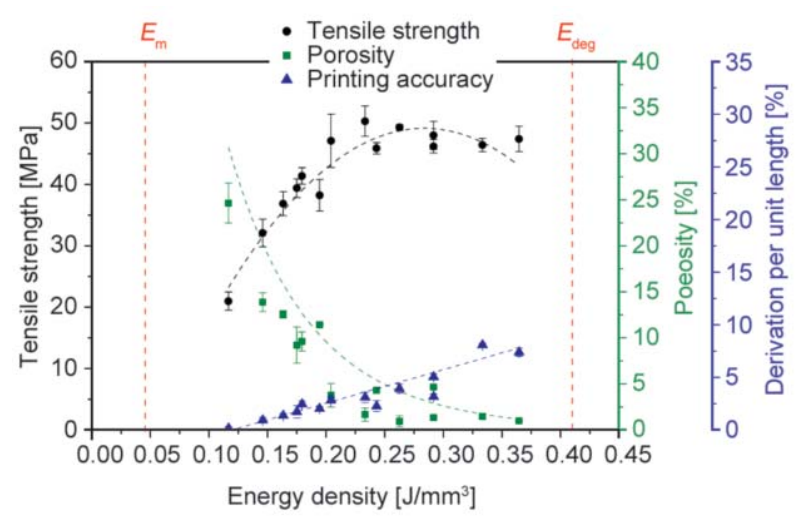

Figure 4. Effect of laser energy density on tensile strength, porosity and dimensional accuracy (deviation per unit length) of PA12/CF sintered samples. 
constant or even slightly decreased when energy density was further raised. Similarly, a progressive decrease of porosity was observed as a function of increasing laser energy input; density values approaching $1.08 \mathrm{~g} / \mathrm{cm}^{3}$ of a fully dense part were reached at energy densities above $0.23-0.24 \mathrm{~J} / \mathrm{mm}^{3}$. As a consequence, the rather poor strength observed when the laser energy input approaches the lower limit of the stable sintering region is mainly due to the high porosity content. Also, the elastic modulus and the elongation at failure of PA12/CF samples greatly increased with laser energy density up to the middle part of the stable sintering region, reaching maximum values of $3200 \mathrm{MPa}$ and $4.7 \%$ respectively.

Figure 5 shows the microstructure of PA12/CF samples sintered using different values of energy density; the variation of pore size and distribution is clearly visible.

So, in principle, it would seem convenient to adopt high energy density values to obtain almost fully dense specimens (Figure 5c) and still prevent

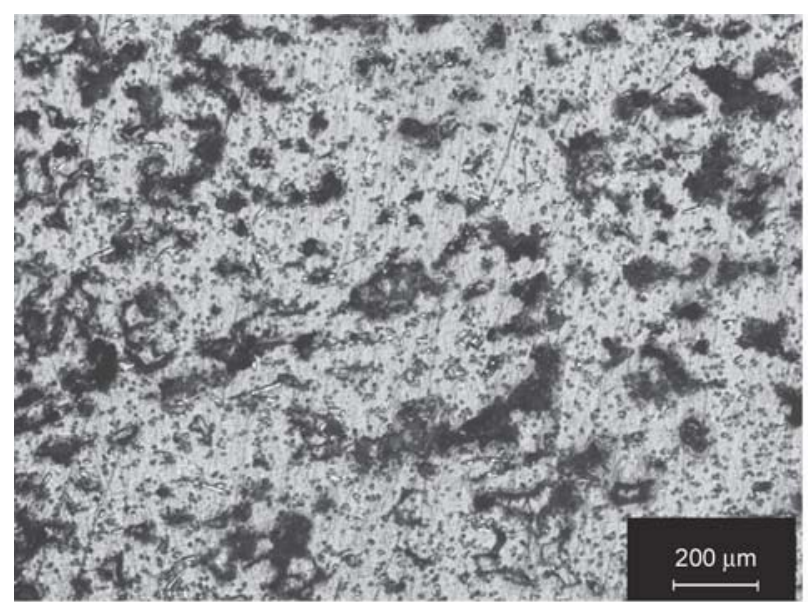

a) degradation. Unfortunately, printing accuracy worsened when energy densities close to the upper limit of the stable sintering region were used. The poor dimensional accuracy of these samples probably arises from an excessive energy input: material overheating and other processing problems such as an inhomogeneous temperature distribution across the powder bed can, in fact, occur. Powder particles that are close to the printed objects partially melt and can adhere to their surface, leading to incorrect parts dimensions [42]. In some cases, thermal stresses built up during the process result in the warping of the printed objects. However, samples with limited deviation from the expected dimensions and porosity lower than $2 \%$ can be obtained by adopting energy density values in the middle part of the stable sintering region.

Theoretically, energy density values are above the lower limit of the stable sintering region. However, samples produced using energy density values just above this limit present a medium or high content of residual porosity, indicating insufficient melting and

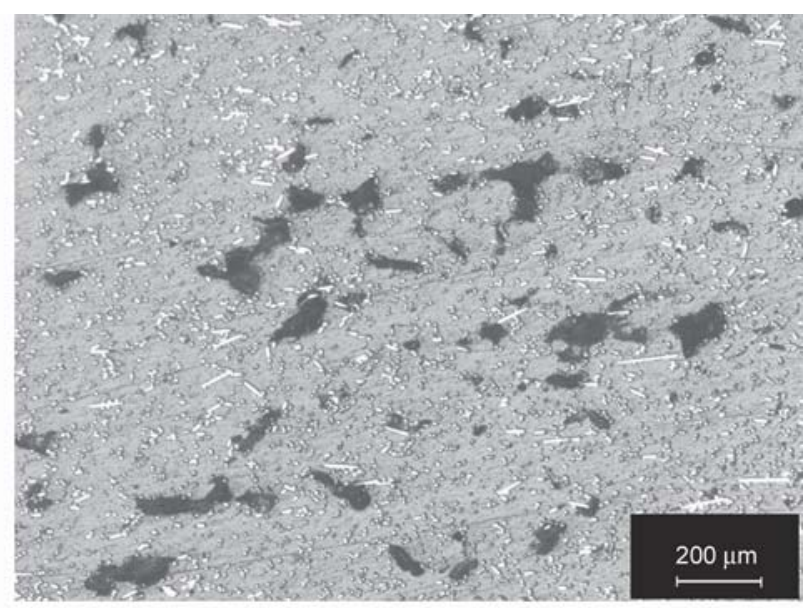

b)

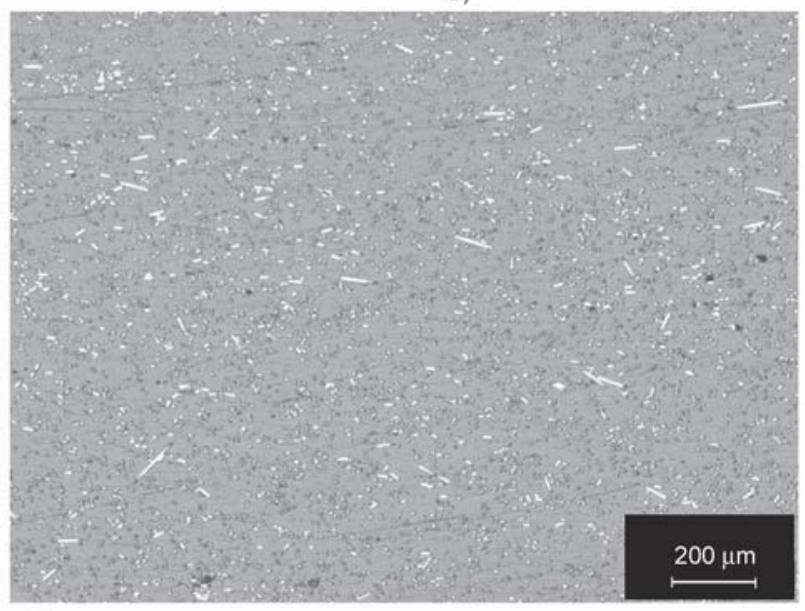

c)

Figure 5. Optical micrographs of $X Z$ cross sections of PA12/CF parts sintered using different laser energy density values: (a) $0.117 \mathrm{~J} / \mathrm{mm}^{3}$, (b) $0.194 \mathrm{~J} / \mathrm{mm}^{3}$, (c) $0.233 \mathrm{~J} / \mathrm{mm}^{3}$. 
coalescence of the powders. Considering the tensile strength and porosity values, a critical energy density per unit volume of $0.23-0.24 \mathrm{~J} / \mathrm{mm}^{3}$ ( 5 times higher than $E_{\mathrm{m}}$ ) could be identified as the minimum laser energy input required to fully sinter this composite. These results support previous findings on polyamide-based materials: both Vasquez et al. [29] and Yuan et al. [27] found that the energy required to effectively sinter polymer powders and produce parts with good mechanical properties is between 4 and 5 times the predicted energy to melt a layer.

Yuan et al. [27] stated that this difference is solely attributed to an inefficient heat absorption of the powder bed and indicated that only $22 \%$ of laser energy input is absorbed by PA12/CNTs composite powders. However, not only the optical properties but also the coalescence kinetics should be considered. In fact, Laumer et al. [43] demonstrated that PA12 powders showed an absorptance coefficient higher than $90 \%$ at $\mathrm{CO}_{2}$ laser wavelength $(10.6 \mu \mathrm{m})$. This reveals that unfilled PA12 absorbs almost all the laser energy supplied during the SLS process because multiple reflections and scattering of the radiation between particles in the powder bed enhance the absorption coefficient of the material. This is particularly true in carbon fillers reinforced composites as these reinforcements typically show high IR-energy absorptance $[6,44]$.

Based on these considerations, the minimum energy input required to fully melt polyamide powders is only slightly higher than the predicted one. Therefore, the difference between $E_{\mathrm{m}}$ and the critical energy required to obtain almost fully dense parts could be attributed to the rheological properties and coalescence kinetics of the powders, as also suggested by other authors [5-7, 45]. In fact, it should be considered that the laser provides energy in a very short time, and afterward, the polymer melt quickly solidifies. It is very likely that the amount of time during which the polymer remains in the molten state is not sufficient to allow the complete coalescence of adjacent powder particles; as an alternative, the viscosity of the melt is too high. These issues could be overtaken by increasing the energy delivered by the laser beam, for example, by using lower scan speed. In this way, the melt pool temperature increases, and the polymer viscosity decreases. In fact, in-depth investigations $[46,47]$ on the effect of the variation of this parameter showed that the rate of energy delivery influences the properties of SLS products: slower scan speeds result in an increase of the laser-polymer interaction time, which in turn could enhance powders coalescence and reduce the residual porosity. $\mathrm{X}$-ray diffraction analyses of specimens sintered at selected energy density values showed that PA12/CF parts produced by SLS have XRD patterns similar to those of raw powders: in addition to the presence of an amorphous phase, a peak emerging from the broad halo, which belongs to $\gamma$ crystalline phase of polyamide 12 was observed at $2 \theta$ around $21^{\circ}$.

Moreover, DSC analyses showed that the crystalline fraction of the polymeric matrix (about 27\%) was significantly lower than that of powdered materials (about 49\%) for all the investigated process parameters (Table 5). This variation can be attributed to differences in the thermal history of the material occurring between the laser sintering process and the powder production method. In fact, SLS process entails a complex heating-cooling cycle during laser exposure followed by slow cooling from the powder bed temperature [48]; on the other hand, during the production of the powder, polymerization and isothermal crystallization from solution take place at $120^{\circ} \mathrm{C}$, leading to higher melting point and enthalpy of fusion compared to standard polyamide grade [31].

The microstructure of the $X Y$ cross-section of the sample produced at $0.233 \mathrm{~J} / \mathrm{mm}^{3}$ shows that the fibers are partially aligned in the $x$-direction of the build chamber (Figure 6a). The orientation of the fibers with respect to the recoater movement direction ( $x$-axis) can be appreciated by examining the angle formed between fiber and this axis by means of image analysis. The resulting orientation distribution histogram reveals that the recoater was able to align some fibers during the deposition of a new layer of powder (Figure 6b).

This finding confirms the results obtained by Jansson and Pejryd [16] on a similar carbon fiber reinforced composite produced by SLS. The reported theory

Table 5. Diffraction peak, melting characteristics and crystalline fraction of raw PA12/CF powders and SLS parts built by using various energy density values obtained from DSC and XRD analysis.

\begin{tabular}{|l|c|c|c|c|}
\hline \multicolumn{1}{|c|}{ Sample } & $\begin{array}{c}\mathbf{( 1 0 0}_{\gamma} \\
{\left[\mathbf{2 \theta}^{\circ}\right]}\end{array}$ & $\begin{array}{c}\boldsymbol{T}_{\mathbf{m}} \\
{\left[{ }^{\circ} \mathbf{C}\right]}\end{array}$ & $\begin{array}{c}\boldsymbol{h}_{\mathbf{f}} \\
{[\mathbf{J} / \mathbf{g}]}\end{array}$ & $\begin{array}{c}\boldsymbol{X}_{\mathbf{C}} \\
{[\mathbf{\%}]}\end{array}$ \\
\hline Powder & 21.4 & 182.3 & 81.4 & 48.1 \\
\hline SLS $\left(E_{\mathrm{D}}=0.117 \mathrm{~J} / \mathrm{mm}^{3}\right)$ & 21.3 & 178.1 & 45.1 & 26.6 \\
\hline $\mathrm{SLS}\left(E_{\mathrm{D}}=0.194 \mathrm{~J} / \mathrm{mm}^{3}\right)$ & 21.4 & 177.8 & 45.4 & 26.8 \\
\hline $\mathrm{SLS}\left(E_{\mathrm{D}}=0.233 \mathrm{~J} / \mathrm{mm}^{3}\right)$ & 21.3 & 178.6 & 46.8 & 27.6 \\
\hline
\end{tabular}




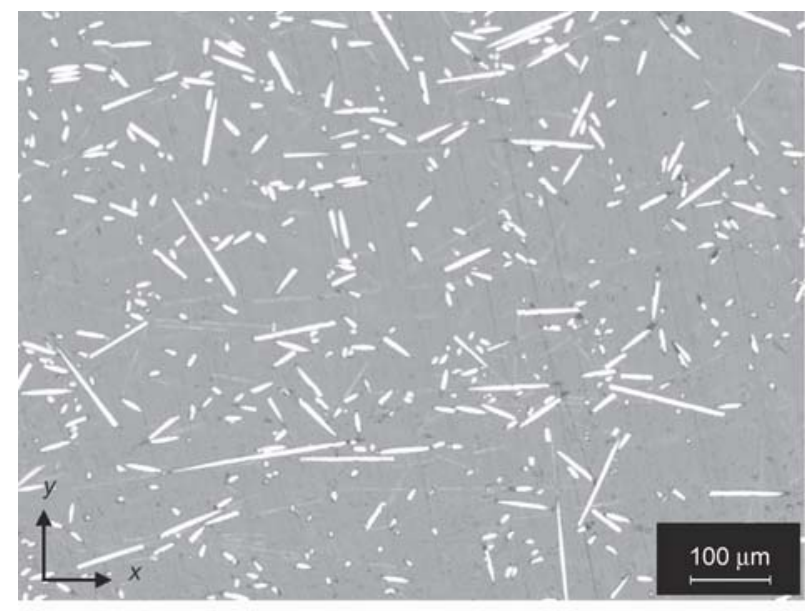

a)

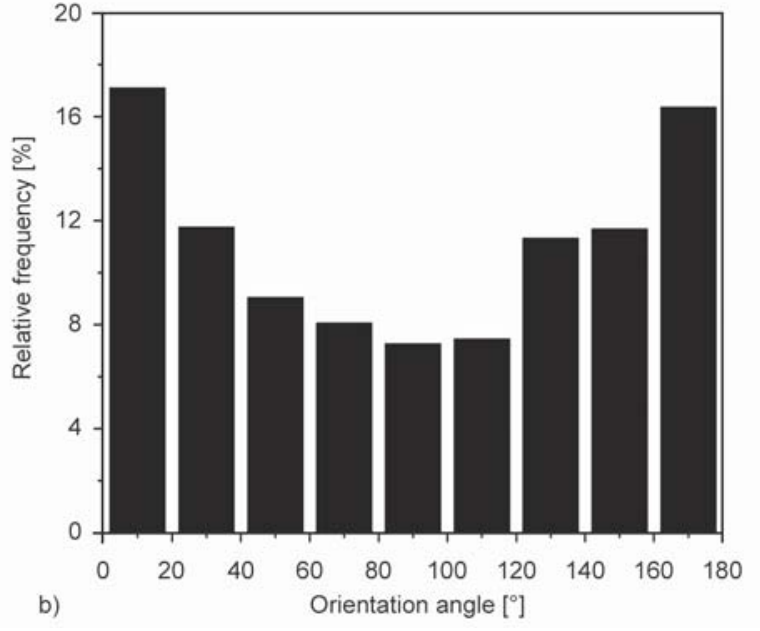

Figure 6. (a) Optical micrographs of XY cross section of a typical PA12/CF sintered part; (b) distribution of fibers orientation with respect to recoater movement direction $\left(0\right.$ and $180^{\circ}$ are parallel to the rake movement while $90^{\circ}$ is perpendicular).

explains the preferential fiber orientation along the $x$-direction as a consequence of the mechanical action of the recoater. The optical image on PA12/CF samples (Figure 6a) supports this theory, showing that almost no fibers are oriented in the $z$-direction (that is perpendicular to the build plane). However, experimental outcomes indicate that the degree of fiber orientation could strictly depend on their length. Only the fibers showing a length that is similar or greater than the layer height are hit by the recoater and tend to align in the $x$-direction. The remaining fibers seem to maintain the random orientation of the raw powders.

\subsubsection{PP}

The influence of laser energy density on tensile strength, porosity, and dimensional accuracy of polypropylene parts is depicted in Figure 7. The tensile test results showed that an increase of laser energy

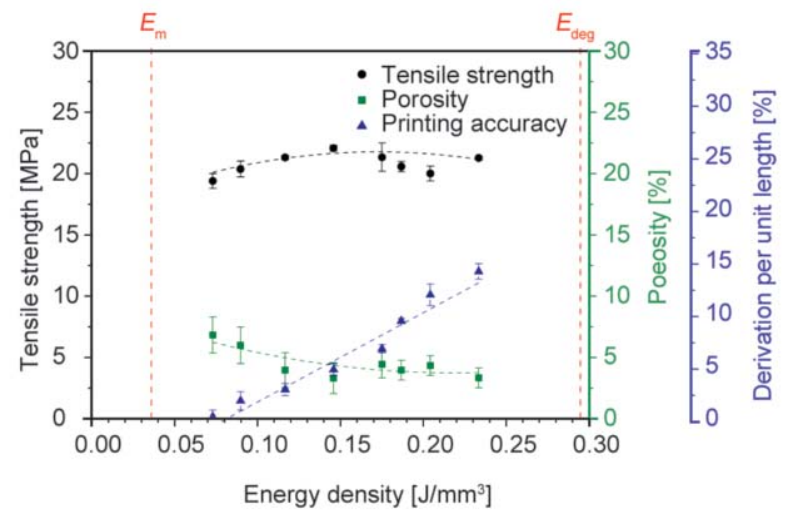

Figure 7. Effect of laser energy density on tensile strength, porosity and dimensional accuracy (deviation per unit length) of PP sintered samples. input allowed an enhancement of mechanical properties. Tensile strength and elongation at break reached values of $22.1 \mathrm{MPa}$ and $49 \%$ respectively in the middle part of the stable sintering region (around $0.15 \mathrm{~J} / \mathrm{mm}^{3}$ ). This critical value also seems appropriate to obtain the lowest level of porosity, although the variation of energy density has only a limited effect on the density of PP parts (Figure 7). Porosities with different size and morphology can be detected from optical micrographs of YZ cross-sections of sintered samples (Figure 8). Pores did not disappear even at rather high energy densities. The residual porosity (about $3 \%$ ) is very likely due to the irregular shape and the wide particle size distribution of PP powders. These characteristics, along with the presence of small particles $(<20 \mu \mathrm{m})$, negatively affect powder bed density, which is directly related to parts density [42]. Moreover, the pore morphology significantly changes: both localized voids among subsequent layers, indicating poor interlayer bonding, and more uniformly distributed voids at increasing laser energy input $[15,27]$ were observed.

Nonetheless, the experimental results clearly showed that large dimensional deviations occurred when high energy input was delivered by the laser beam. In order to limit this geometrical inaccuracy, the energy density should not exceed the middle part of the stable sintering region (around $0.15-0.17 \mathrm{~J} / \mathrm{mm}^{3}$ ). In addition, at high energy densities, severe warping of the specimens was observed. This deformation makes difficult the correct positioning of the extensometer and gives rise to stress concentration at extensometer knife-edges. Therefore, reliable measurement of the 


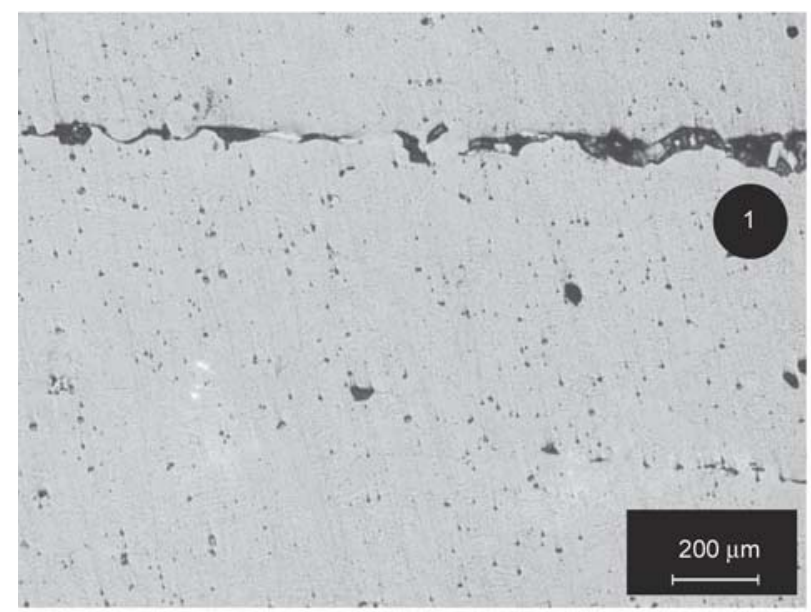

a)

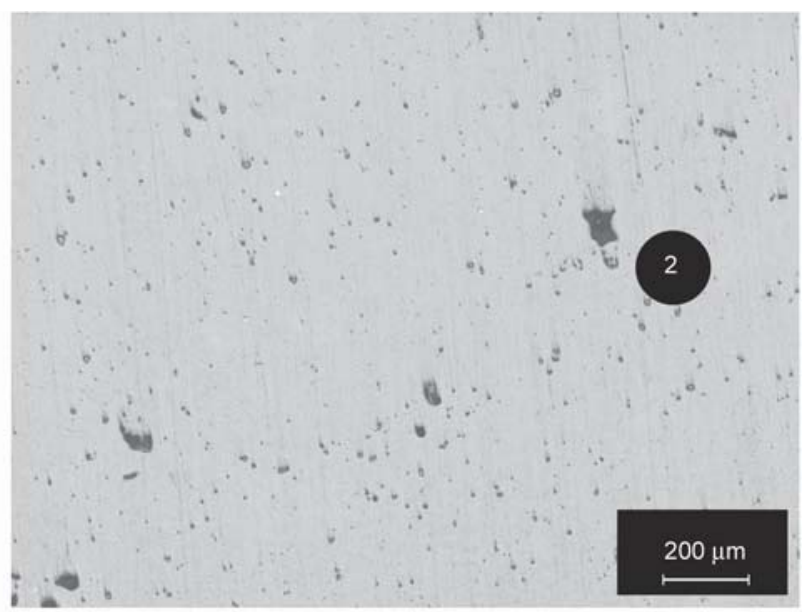

b)

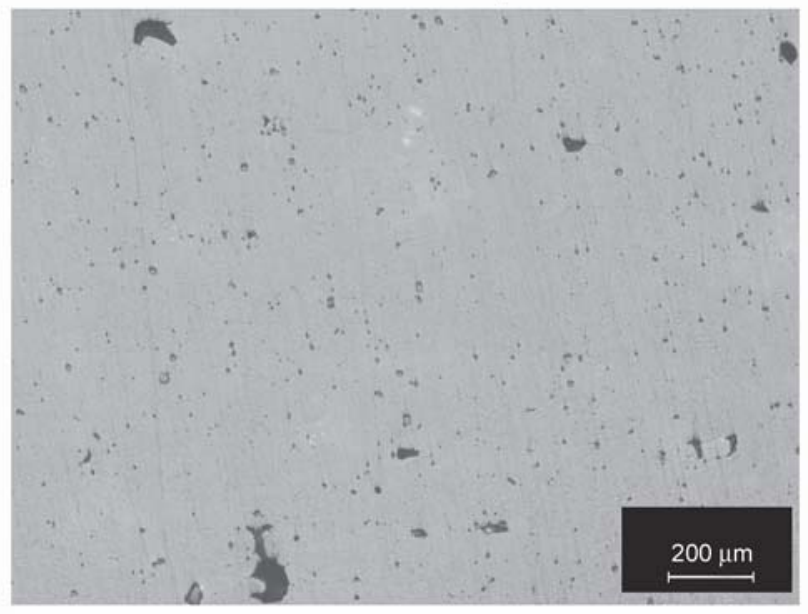

c)

Figure 8. Optical micrographs showing the microstructure of PP parts sintered at different laser energy density values: (a) $0.073 \mathrm{~J} / \mathrm{mm}^{3}$, (b) $0.146 \mathrm{~J} / \mathrm{mm}^{3}$, (c) $0.233 \mathrm{~J} / \mathrm{mm}^{3}$. Different types of porosity are highlighted: inter-layer voids (1) and uncompleted sintering voids (2).

elastic modulus and elongation at break was hindered, and la arge dispersion of elongation values was found.

PP parts produced by laser sintering show some microstructural differences from the raw powders. In fact, both $\alpha$ and $\gamma$ crystalline phases of polypropylene were found in the sintered specimens. The presence of two crystalline phases was highlighted by the diffraction peaks in XRD patterns [20,38], as well as by two melting peaks shown in the DCS traces at 130 and $141^{\circ} \mathrm{C}$ respectively.
It was possible to determine that about $60 \%$ of the crystalline fraction of the sintered polymer can be attributed to $\gamma$ phase by using the Equation (9):

$K_{\gamma}=\frac{H_{\gamma}}{H_{\gamma}+H_{\alpha}} \cdot 100 \%$

where $H_{\gamma}$ and $H_{\alpha}$ are the intensities of XRD peaks at $2 \theta=18.6^{\circ}$ and $20.07^{\circ}$, corresponding to $(130)_{\alpha}$ and (117) $\gamma$ lattice planes [20]. Moreover, the crystalline fraction of the printed parts (about 34\%) was very close to that observed in the raw powders. The degree

Table 6. Melting characteristics, crystalline phases and contents of $\gamma$ phase of the raw PP powders and SLS specimens built by using various energy densities obtained from DSC and XRD analysis.

\begin{tabular}{|l|c|c|c|c|c|c|c|}
\hline \multicolumn{1}{|c|}{ Sample } & $\begin{array}{c}(\mathbf{1 3 0})_{\boldsymbol{\alpha}} \\
{\left[\mathbf{2 0}^{\circ}\right]}\end{array}$ & $\begin{array}{c}(\mathbf{1 1 7})_{\boldsymbol{\gamma}} \\
{\left[\mathbf{2 0}^{\circ}\right]}\end{array}$ & $\begin{array}{c}\boldsymbol{K}_{\gamma} \\
{[\mathbf{\%}]}\end{array}$ & $\begin{array}{c}\boldsymbol{T}_{\mathbf{m} \mathbf{1}} \\
{\left[{ }^{\mathbf{O}} \mathbf{C}\right]}\end{array}$ & $\begin{array}{c}\boldsymbol{T}_{\mathbf{m} \mathbf{2}} \\
{\left[{ }^{\circ} \mathbf{C}\right]}\end{array}$ & $\begin{array}{c}\boldsymbol{h}_{\mathbf{f}} \\
{[\mathbf{J} / \mathbf{g}]}\end{array}$ & $\begin{array}{c}\boldsymbol{X}_{\mathbf{C}} \\
{[\mathbf{\%}]}\end{array}$ \\
\hline Powder & 18.3 & - & 0 & 137.5 & - & 59.4 & 32.7 \\
\hline SLS $\left(E_{\mathrm{D}}=0.073 \mathrm{~J} / \mathrm{mm}^{3}\right)$ & 18.6 & 20.1 & 62.4 & 131.7 & 141.4 & 60.9 & 34.4 \\
\hline SLS $\left(E_{\mathrm{D}}=0.146 \mathrm{~J} / \mathrm{mm}^{3}\right)$ & 18.6 & 20.0 & 61.3 & 129.9 & 141.0 & 61.6 & 34.8 \\
\hline SLS $\left(E_{\mathrm{D}}=0.233 \mathrm{~J} / \mathrm{mm}^{3}\right)$ & 18.6 & 20.1 & 61.8 & 129.9 & 141.4 & 60.0 & 33.8 \\
\hline
\end{tabular}


of crystallinity and the proportion between $\alpha$ and $\gamma$ phases remain almost constant irrespectively from the process parameters used, as reported in Table 6 .

\section{Conclusions}

Selective laser sintering of polymer-based materials has been attracting increasing interest in the last years. However, the number of polymer powders suitable for this technology is limited and remains one of the major limitations of this process. In addition, the strategy currently adopted for evaluating new polymer powders and optimizing the sintering process is based on a trial-and-error approach. This method is highly inefficient in terms of time and cost.

A more analytical approach, offering the potential to save time and material whilst improving part consistency, entails the greatest interest. Few theoretical methods have been reported in the literature to correlate the intrinsic properties of the powders with process parameters and part performance. In this context, this work exploits the stable sintering region analysis to show that the combination of different criteria (such as mechanical properties, dimensional accuracy, and defect content) can be used to optimize the laser exposure parameters used in the SLS process.

The properties of two different polymer-based powders (PA12/CF and PP, respectively) were characterized to identify the supercooling window and to calculate the energy required for melting and degradation. The results showed that a wide laser energy input range is applicable for laser sintering avoiding polymer degradation. However, it was found that the stable sintering region can be further restricted. In fact, the best combination of part densification, mechanical properties, and dimensional accuracy was achieved by using energy density values within the middle part of this region. Samples with high porosity levels and poor mechanical performance were produced when energy density approaches the lower limit. On the other hand, an increase of the energy input near to the degradation limit leads to incorrect part dimensions or even distortion before the polymer starts decomposing.

Moreover, the morphology of the polymeric particles greatly influences the mechanical properties of SLS built parts. Powders with irregular shape and large particle size distribution (this is the case of PP) showed limited processability and low mechanical performances.
This experimental work demonstrates that an accurate investigation of the stable sintering region is useful to reduce the number of trials required to optimize the SLS process parameters. However, the extrinsic properties of the powders (such as particle size distribution and shape) also entail great significance in final part performance.

To further validate the proposed approach, other materials should be tested.

\section{Acknowledgements}

The authors acknowledge that this research has been performed in the frame of a joint project with Fiat Research Center (CRF): 'Additive manufacturing of polymer-based composites with enhanced mechanical behavior and electrical functionalities.' The authors also thank Antonio Favero for performing mechanical tests and Mauro Raimondo for FESEM analysis.

\section{References}

[1] Goodridge R., Ziegelmeier S.: Powder bed fusion of polymers. in 'Laser additive manufacturing: Materials, design, technologies, and applications' (ed: Brandt M.) Elsevier, Amsterdam, 181-204 (2017).

[2] Ligon S. C., Liska R., Stampfl J., Gurr M., Mülhaupt R.: Polymers for $3 \mathrm{D}$ printing and customized additive manufacturing. Chemical Reviews, 117, 10212-10290 (2017).

https://doi.org/10.1021/acs.chemrev.7b00074

[3] Yuan S., Shen F., Chua C. K., Zhou K.: Polymeric composites for powder-based additive manufacturing: Materials and applications. Progress in Materials Science, 91, 141-168 (2019). https://doi.org/10.1016/j.progpolymsci.2018.11.001

[4] Goodridge R. D., Tuck C. J., Hague R. J. M.: Laser sintering of polyamides and other polymers. Progress in Materials Science, 57, 229-267 (2012). https://doi.org/10.1016/j.pmatsci.2011.04.001

[5] Schmid M., Amado A., Wegener K.: Materials perspective of polymers for additive manufacturing with selective laser sintering. Journal of Materials Research, 29, 1824-1832 (2014). https://doi.org/10.1557/jmr.2014.138

[6] Chatham C. A., Long T. E., Williams C. B.: A review of the process physics and material screening methods for polymer powder bed fusion additive manufacturing. Progress in Materials Science, 93, 68-95 (2019). https://doi.org/10.1016/j.progpolymsci.2019.03.003

[7] Verbelen L., Dadbakhsh S., van den Eynde M., Kruth J-P., Goderis B., van Puyvelde P.: Characterization of polyamide powders for determination of laser sintering processability. European Polymer Journal, 75, 163-174 (2016). https://doi.org/10.1016/j.eurpolymj.2015.12.014 
[8] Vasquez G. M., Majewski C. E., Haworth B., Hopkinson N.: A targeted material selection process for polymers in laser sintering. Additive Manufacturing, 1-4, 127 138 (2014). https://doi.org/10.1016/j.addma.2014.09.003

[9] Dupin S., Lame O., Barrès C., Charmeau J-Y.: Microstructural origin of physical and mechanical properties of polyamide 12 processed by laser sintering. European Polymer Journal, 48, 1611-1621 (2012). https://doi.org/10.1016/j.eurpolymj.2012.06.007

[10] Stichel T., Frick T., Laumer T., Tenner F., Hausotte T., Merklein M., Schmidt M.: A round robin study for selective laser sintering of polymers: Back tracing of the pore morphology to the process parameters. Journal of Materials Processing Technology, 252, 537-545 (2018). https://doi.org/10.1016/j.jmatprotec.2017.10.013

[11] Flodberg G., Pettersson H., Yang L.: Pore analysis and mechanical performance of selective laser sintered objects. Additive Manufacturing, 24, 307-315 (2018). https://doi.org/10.1016/j.addma.2018.10.001

[12] Caulfield B., McHugh P. E. Lohfeld S.: Dependence of mechanical properties of polyamide components on build parameters in the SLS process. Journal of Materials Processing Technology, 182, 477-488 (2007). https://doi.org/10.1016/j.jmatprotec.2006.09.007

[13] Starr T. L., Gornet T. J., Usher J. S.: The effect of process conditions on mechanical properties of lasersintered nylon. Rapid Prototyping Journal, 17, 418-423 (2011). https://doi.org/10.1108/13552541111184143

[14] Pilipović A., Brajlih T., Drstvenšek I.: Influence of processing parameters on tensile properties of SLS polymer product. Polymers, 10, 1208/1-1208/18 (2018). https://doi.org/10.3390/polym10111208

[15] Zhu W., Yan C., Shi Y., Wen S., Han C., Cai C., Liu J., Shi Y: Study on the selective laser sintering of a lowisotacticity polypropylene powder. Rapid Prototyping Journal, 22, 621-629 (2016). https://doi.org/10.1108/RPJ-02-2015-0014

[16] Jansson A., Pejryd L.: Characterisation of carbon fibrereinforced polyamide manufactured by selective laser sintering. Additive Manufacturing, 9, 7-13 (2016). https://doi.org/10.1016/j.addma.2015.12.003

[17] Jing W., Hui C., Qiong W., Hongbo L., Zhanjun L.: Surface modification of carbon fibers and the selective laser sintering of modified carbon fiber/nylon 12 composite powder. Materials and Design, 116, 253-260 (2017). https://doi.org/10.1016/j.matdes.2016.12.037

[18] Yan C., Hao L., Xu L., Shi Y.: Preparation, characterisation and processing of carbon fibre/polyamide-12 composites for selective laser sintering. Composites Science and Technology, 71, 1834-1841 (2011). https://doi.org/10.1016/j.compscitech.2011.08.013

[19] Ituarte I. F., Wiikinkoski O., Jansson A.: Additive manufacturing of polypropylene: A screening design of experiment using laser-based powder bed fusion. Polymers, 10, 1293/1-1293/16 (2018).

https://doi.org/10.3390/polym10121293
[20] Zhu W., Yan C., Shi Y., Wen S., Liu J., Shi Y.: Investigation into mechanical and microstructural properties of polypropylene manufactured by selective laser sintering in comparison with injection molding counterparts. Materials and Design, 82, 37-45 (2015).

https://doi.org/10.1016/j.matdes.2015.05.043

[21] Dadbakhsh S., Verbelen L., Vandeputte T., Strobbe D., van Puyvelde P., Kruth J-P.: Effect of powder size and shape on the SLS processability and mechanical properties of a TPU elastomer. Physics Procedia, 83, 971980 (2016).

https://doi.org/10.1016/j.phpro.2016.08.102

[22] Berretta S., Evans K. E., Ghita O. R.: Predicting processing parameters in high temperature laser sintering (HT-LS) from powder properties. Materials and Design, 105, 301-314 (2016). https://doi.org/10.1016/j.matdes.2016.04.097

[23] Zeng Z., Deng X., Cui J., Jiang H., Yan S., Peng B.: Improvement on selective laser sintering and post-processing of polystyrene. Polymers, 11, 956/1-956/15 (2019). https://doi.org/10.3390/polym11060956

[24] Gu H., AlFayez F., Ahmed T., Bashir Z.: Poly(ethylene terephthalate) powder - A versatile material for additive manufacturing. Polymers, 11, 2041/1-2041/18 (2019). https://doi.org/10.3390/polym11122041

[25] Hofland E. C., Baran I., Wismeijer D. A.: Correlation of process parameters with mechanical properties of laser sintered PA12 parts. Advances in Materials Science and Engineering, 2017, 4953173/1-4953173/11 (2017).

https://doi.org/10.1155/2017/4953173

[26] Stoia D. I., Marşavina L., Linul E.: Correlations between process parameters and outcome properties of laser-sintered polyamide. Polymers, 11, 1850/1-1850/15 (2019). https://doi.org/10.3390/polym11111850

[27] Yuan S., Bai J., Chua C. K., Wei J., Zhou K.: Material evaluation and process optimization of CNT-coated polymer powders for selective laser sintering. Polymers, 8, 370/1-370/17 (2016).

https://doi.org/10.3390/polym8100370

[28] Vasquez M., Hawort B., Hopkinson N.: Optimum sintering region for laser sintered nylon-12. Proceedings of the Institution of Mechanical Engineers Part B: Journal of Engineering Manufacture, 225, 2240-2248 (2011). https://doi.org/10.1177/0954405411414994

[29] Vasquez M., Haworth B., Hopkinson N.: Methods for quantifying the stable sintering region in laser sintered polyamide-12. Polymer Engineering and Science, 53, 1230-1240 (2013). https://doi.org/10.1002/pen.23386

[30] Schmid M., Kleijnen R., Vetterli M., Wegener K.: Influence of the origin of polyamide 12 powder on the laser sintering process and laser sintered parts. Applied Sciences, 7, 462/1-462/15 (2017). https://doi.org/10.3390/app7050462 
[31] Loyen K., Senff H., Pauly F-X.: Process for the manufacture of polyamide-12 powder with a high melting point. U.S. Patent 8124686 B2, USA (2012).

[32] Schmid M., Amado F., Levy G., Wegener K.: Flowability of powders for selective laser sintering (SLS) investigated by round robin test. in 'Proceedings of the $6^{\text {th }}$ International Conference on Advanced Research in Virtual and Rapid Prototyping. Leiria, Portugal' 95-99 (2013).

[33] van den Eynde M., Verbelen L., van Puyvelde P.: Assessing polymer powder flow for the application of laser sintering. Powder Technology, 286, 151-155 (2015). https://doi.org/10.1016/j.powtec.2015.08.004

[34] Ziegelmeier S., Christou P., Wöllecke F., Tuck C., Goodridge R., Hague R., Krampe E., Wintermantel E.: An experimental study into the effects of bulk and flow behaviour of laser sintering polymer powders on resulting part properties. Journal of Materials Processing Technology, 215, 239-250 (2015). https://doi.org/10.1016/j.jmatprotec.2014.07.029

[35] ASTM E1269-01: Standard test method for determining specific heat capacity by differential scanning calorimetry (2001).

[36] Vyazovkin S., Burnham A. K., Criado J. M., PérezMaqueda L. A., Popescu C., Sbirrazzuoli N.: ICTAC kinetics committee recommendations for performing kinetic computations on thermal analysis data. Thermochimica Acta, 520, 1-19 (2011).

https://doi.org/10.1016/j.tca.2011.03.034

[37] Chen P., Tang M., Zhu W., Yang L., Wen S., Yan C., Ji Z., Nan H., Shi Y.: Systematical mechanism of Polyamide-12 aging and its micro-structural evolution during laser sintering. Polymer Testing, 67, 370-379 (2018). https://doi.org/10.1016/j.polymertesting.2018.03.035

[38] Auriemma F., de Rosa C., Malafronte A., Scoti M.: Polypropylene handbook. Morphology, blends and composites. Springer, New York (2019).

[39] Xi S., Zhang P., Huang Y., Kong M., Yang Q., Li G.: Laser sintering of cryogenically ground polymer powders into high-performance parts: The role of dry particle coating with a conductive flow agent. Polymer, 186, 122044/1-122044/10 (2020).

https://doi.org/10.1016/j.polymer.2019.122044
[40] Sutton A. T., Kriewall C. S., Leu M. C., Newkirk J. W.: Powder characterisation techniques and effects of powder characteristics on part properties in powder-bed fusion processes. Virtual and Physical Prototyping, 12, 329 (2017).

https://doi.org/10.1080/17452759.2016.1250605

[41] Natta G., Pasquon I., Zambelli A., Gatti G.: Dependence of the melting point of isotactic polypropylenes on their molecular weight and degree of stereospecificity of different catalytic systems. Die Makromolekulare Chemie, 70, 191-205 (1964).

https://doi.org/10.1002/macp.1964.020700114

[42] Schmid M., Wegener K.: Additive manufacturing: Polymers applicable for laser sintering (LS). Procedia Engineering, 149, 457-464 (2016).

https://doi.org/10.1016/j.proeng.2016.06.692

[43] Laumer T., Stichel T., Nagulin K., Schmidt M.: Optical analysis of polymer powder materials for selective laser sintering. Polymer Testing, 56, 207-213 (2016). https://doi.org/10.1016/j.polymertesting.2016.10.010

[44] Ho H. C. H., Cheung W. L., Gibson I.: Effects of graphite powder on the laser sintering behaviour of polycarbonate. Rapid Prototyping Journal, 8, 233-242 (2002). https://doi.org/10.1108/13552540210441148

[45] Shi Y., Li Z., Sun H., Huang S., Zeng F.: Effect of the properties of the polymer materials on the quality of selective laser sintering parts. Proceedings of the Institution of Mechanical Engineers Part L: Journal of Materials: Design and Applications, 218, 247-252 (2004). https://doi.org/10.1177/146442070421800308

[46] Drexler M., Lexow M., Drummer D.: Selective laser melting of polymer powder - Part mechanics as function of exposure speed. Physics Procedia, 78, 328-336 (2015). https://doi.org/10.1016/j.phpro.2015.11.047

[47] Shen F., Yuan S., Chua C. K., Zhou K.: Development of process efficiency maps for selective laser sintering of polymeric composite powders: Modeling and experimental testing. Journal of Materials Processing Technology, 254, 52-59 (2018). https://doi.org/10.1016/j.jmatprotec.2017.11.027

[48] Drummer D., Greiner S., Zhao M., Wudy K.: A novel approach for understanding laser sintering of polymers. Additive Manufacturing, B, 379-388 (2019). https://doi.org/10.1016/j.addma.2019.03.012 